\title{
Family heterozygosity and progeny body length in pink salmon Oncorhynchus gorbuscha (Walbaum)
}

\author{
YURI E. DUBROVA*, ELENA A. SALMENKOVA, YURI P. ALTUKHOV, YURI F. \\ KARTAVTSEV $\dagger$, ELENA V. KALKOVA \& VLADIMIR T. OMEL'CHENKO† \\ Vavilov Institute of General Genetics, Russian Academy of Sciences, 3 Gubkin Street, Moscow 117809 and IInstitute of \\ Marine Biology, Far East Branch, Russian Academy of Sciences, 17 Palchevski Street, Vladivostok 690041, Russia
}

\begin{abstract}
The relationship between multiple-locus heterozygosity at eight polymorphic enzyme loci and progeny body length was examined in 20 experimental pink salmon families differing in parental heterozygosity. It was shown that: (1) the effect of individual heterozygosity on body length within the families was not statistically significant; (2) a considerable part of the between-family component of variance of body length was largely attributed to the differences in family heterozygosity; (3) there was no association between the mean family heterozygosity and the coefficient of variation of body length. In the groups of families with the low, intermediate and high heterozygosity the highest value of mean progeny body length was recorded in the intermediate heterozygosity group. There was no significant effect of heterozygosity at single loci on these differences among families. The results are explained by the hypothesis of epistasis and the hypothesis of maintenance of an optimal heterozygosity level in populations.
\end{abstract}

Keywords: epistasis, growth, heterozygosity optimum, isozymes, Oncorhynchus gorbuscha, salmon.

\section{Introduction}

One of the approaches to the problem of the adaptive value of biochemical polymorphism is investigation of relationships between polygenic traits relating to fitness and polymorphic enzyme loci (Altukhov, 1989a). In some studies an association between quantitative traits and heterozygosity at polymorphic loci has been demonstrated while other authors have failed to find it (see Mitton \& Grant, 1984; Zouros, 1987, for a review). A number of theoretical models has been proposed to explain these results (Lerner, 1954; Livshits \& Kobyliansky, 1984; Smouse, 1986; Chakraborty, 1987; Zouros \& Foltz, 1987; Altukhov, 1989b; Dubrova \& Gavrilets, 1989).

Positive associations between heterozygosity at allozyme loci and growth rate have been found in natural populations of fish and marine bivalves as well as among the progeny of mass mating (Zouros et al., 1980; Danzmann et al., 1986, 1987, 1988). However,

${ }^{*}$ Correspondence: Department of Genetics, University of Leicester, Adrian Building, Leicester LE1 7RH, U.K. studies on the progeny of individual crosses have failed to find any correlations between heterozygosity and phenotypic characters (Beaumont et al., 1983; Gaffney \& Scott, 1984; Foltz \& Chatry, 1986; Mallet et al., 1986; Ferguson, 1992). These results might suggest that these associations are largely the consequence of linkage disequilibrium between allozyme loci and other loci that affect the traits being studied (Zouros \& Foltz, 1987).

In our previous studies the associations between allozyme heterozygosity and components of fitness were investigated in one species of Pacific salmon, the pink salmon Oncorhynchus gorbuscha (Walbaum) (Altukhov, 1989b; Kartavtsev, 1990; Kartavtsev et al., 1990; Altukhov et al., 1991). In experimental crosses of parents with different multiple-locus heterozygosity at enzyme loci, the effect of parental heterozygosity on the viability and body length of progeny was shown. The progeny of parents with the intermediate heterozygosity had the lowest mortality. At the same time the variance of body length increased with parental heterozygosity. The positive correlation of the individual heterozygosity (number of heterozygous loci per 
individual) and body length was demonstrated in these experiments. These results, however, were obtained using a limited number of families and only four polymorphic loci. The aim of the present study is to verify these effects for a greater number of allozyme genes and in a larger set of crosses.

\section{Materials and methods}

The experiment was conducted at the Sokolovsky hatchery and the 'Sokol' Biological Station of the Institute of Marine Biology, Far East Branch of Russian Academy of Sciences (South Sakhalin). In September 1989 eight mature males and ten mature females were chosen for crossing from 300 pink salmon spawners with known allozyme genotypes; their weights and body lengths were measured. $2 \times 2$ diallel crosses were conducted, i.e. the eggs of each of two females were divided into two approximately equal portions, each of which was fertilized by half of the sperm of one of two males. Two males were used twice in diallel crosses with different females. The fertilized eggs of each cross were incubated separately; the progeny of each cross was reared in an individual nurse pond. Thus, we obtained 20 families that constituted five sets of halfsib progeny (see Table 1). During the incubation and rearing, dead progeny (eggs, larvae or fry) were periodically removed. In late May 1990 before catadromic migration, the progeny fry were collected from the nurse ponds and frozen at $-15^{\circ} \mathrm{C}$. Directly before analysis they were thawed and measured using a MBS9 binocular micrometer. The body length was measured from the tip of the snout to the caudal fin and expressed in micrometer units. Then genotypes for allozyme loci were determined.

Genotypes of the spawners and the progeny were scored by starch and polyacrylamide gel electrophoresis (Salmenkova \& Omel'chenko, 1983). Seven polymorphic enzymes encoded by the eight loci listed in Table 1 were analysed. The allele segregation at the $\mathrm{MDH}-3,4^{*}$ isoloci in the progeny showed that the male no. 3, the father of G1-2 and G1-4, was heterozygous at both loci; therefore in these families the $M D H^{*}$ alleles were arbitrarily attributed to the separate loci $M D H-3^{*}$ and $M D H-4^{*}$ so that only the double heterozygotes at the $M D H-3,4^{*}$ loci are considered as heterozygotes at the $M D H-3^{*}$ locus. In the other families only one $M D H^{*}$ locus was heterozygous and it was arbitrarily designated $\mathrm{MDH}-4^{*}$.

All statistical procedures are given by Sokal \& Rohlf (1981) and Hollander \& Wolfe (1973).

\section{Results}

\section{Individual heterozygosity and progeny body length}

Body length of pink salmon fry is affected by numerous biological and environmental factors such as egg size, body length of parents, incubation and rearing conditions, etc. (Zhivotovsky et al., 1987; Beacham, 1988). The influence of some of these factors cannot be quantified, but they can bias the relationship between the parental genotypes and body length of the progeny determined in a limited number of families. Therefore, we tested the data on progeny body length for homogeneity. The overall mean body length in all families was $162.9 \pm 0.1$ (standard deviation, $\mathrm{SD}=6.19$ ); therefore 95 per cent of the distribution of body length lay within the limits $162.9 \pm(2 \times 6.19)$. Thus fry with body length less than 151 or more than 175 units can be considered as deviations. Their percentages in each of the families are given in Table 1. Two families of the $G 2$ set (G2-3, G2-4) and two families of the G5 set (G5-3, G5-4) had unusually high numbers of progeny with high and low body length values, respectively. As was expected from the effect of the female size on the larval body length (Zhivotovsky et al., 1987), the fry of these families turned out to be the progeny of the smallest and largest females used in the crosses. To avoid the above-mentioned bias, a new set of 16 families with 2565 progeny in which these four deviant families had been excluded was also used in the subsequent analysis. Fig. 1 presents the distribution of body length among two sets of families which appears to be close to a normal distribution after the exclusion of the four deviant families.

Table 2 presents the mean body length in the progeny from the families with different parental heterozygosities. The one-way ANOVA revealed substantial differences between families (Table 3), which suggest a considerable genetic component of the variance of fry body length for both sets of families. Such pronounced interfamily differentiation complicates further analysis. The data in Table 3 show that fry heterozygosity also causes a statistically significant effect on body length. Therefore, for the adequate analysis of the heterozygosity effect on progeny body length we applied the nested ANOvA which allows consideration of the joint effects of several factors. Using this technique, we tested the effect of individual heterozygosity on body length within only 18 families ( 20 families set) or 15 families ( 16 families set) in which at least one locus was polymorphic. The differences between families were substantial, but the individual heterozygosity had no influence on the body length within families (Table 4). In other words, the results 
Table 1 Types of crosses and characteristics of pink salmon parents and progeny

\begin{tabular}{|c|c|c|c|c|c|c|c|c|c|c|c|c|c|c|}
\hline \multirow[b]{2}{*}{ Set } & \multirow[b]{2}{*}{ Family $\dagger$} & \multicolumn{3}{|c|}{ Parents } & \multicolumn{8}{|c|}{ Parental genotypes } & \multirow[b]{2}{*}{$N(E \%) \ddagger$} & \multirow[b]{2}{*}{$H \S$} \\
\hline & & $\begin{array}{l}\text { No. } \\
\text { sex }\end{array}$ & $\begin{array}{l}\text { Length } \\
(\mathrm{cm})\end{array}$ & $\begin{array}{c}\text { Weight } \\
(\mathrm{kg})\end{array}$ & $G 3 P D H^{*}$ & $M D H-3^{*}$ & $M D H-4^{*}$ & $M E P-2^{*}$ & ${ }^{*} P G D H^{*}$ & ${ }^{*} P G M^{*}$ & $G P I-2^{*}$ & ${ }^{*} F D H^{*}$ & & \\
\hline \multirow[t]{8}{*}{ G1 } & \multirow{2}{*}{ G1-1 (1) } & 10 & 53 & 1.0 & $1 / 1$ & $1 / 1$ & $1 / 1$ & $1 / 1$ & $1 / 1$ & $1 / 1$ & $1 / 1$ & $1 / 1$ & \multirow[t]{2}{*}{$149(0)$} & \multirow[t]{2}{*}{$0(1)$} \\
\hline & & $2 q$ & 53 & 1.0 & $1 / 1$ & $1 / 1$ & $1 / 1$ & $1 / 1$ & $1 / 1$ & $1 / 1$ & $1 / 1$ & $1 / 1$ & & \\
\hline & \multirow[t]{2}{*}{ G1-2(2) } & $30^{\circ}$ & 54 & 1.3 & $1 / 1$ & $1 / 2$ & $1 / 2$ & $1 / 1$ & $1 / 2$ & $1 / 1$ & $1 / 1$ & $1 / 1$ & \multirow{2}{*}{$150(0)$} & \multirow{2}{*}{$1.52(2)$} \\
\hline & & $2 \%$ & 53 & 1.0 & $1 / 1$ & $1 / 1$ & $1 / 1$ & $1 / 1$ & $1 / 1$ & $1 / 1$ & $1 / 1$ & $1 / 1$ & & \\
\hline & \multirow[t]{2}{*}{ G1-3(3) } & 10 & 53 & 1.0 & $1 / 1$ & $1 / 1$ & $1 / 1$ & $1 / 1$ & $1 / 1$ & $1 / 1$ & $1 / 1$ & $1 / 1$ & \multirow[t]{2}{*}{$189(0)$} & \multirow[t]{2}{*}{$0.46(1)$} \\
\hline & & 49 & 48 & 0.8 & $1 / 1$ & $1 / 1$ & $1 / 1$ & $1 / 1$ & $1 / 2$ & $1 / 1$ & $1 / 1$ & $1 / 1$ & & \\
\hline & \multirow[t]{2}{*}{$\mathrm{G} 1-4(4)$} & $30^{\circ}$ & 54 & 1.3 & $1 / 1$ & $1 / 2$ & $1 / 2$ & $1 / 1$ & $1 / 2$ & $1 / 1$ & $1 / 1$ & $1 / 1$ & \multirow{2}{*}{$144(0.7)$} & \multirow{2}{*}{$1.48(2)$} \\
\hline & & 49 & 48 & 0.8 & $1 / 1$ & $1 / 1$ & $1 / 1$ & $1 / 1$ & $1 / 2$ & $1 / 1$ & $1 / 1$ & $1 / 1$ & & \\
\hline \multirow[t]{8}{*}{$\mathrm{G} 2$} & \multirow[t]{2}{*}{$\mathrm{G} 2-1(5)$} & $50^{\circ}$ & 52 & 1.1 & $1 / 1$ & $1 / 1$ & $1 / 3$ & $1 / 2$ & $1 / 2$ & $1 / 2$ & $1 / 1$ & $1 / 1$ & $150(1.3)$ & $2.52(3)$ \\
\hline & & 69 & 53 & 1.0 & $1 / 2$ & $1 / 1$ & $1 / 1$ & $1 / 1$ & $1 / 1$ & $1 / 2$ & $1 / 1$ & $1 / 1$ & & \\
\hline & G2-2(6) & $70^{\circ}$ & 50 & 1.0 & $1 / 1$ & $1 / 1$ & $1 / 1$ & $1 / 2$ & $1 / 2$ & $1 / 1$ & $1 / 2$ & $1 / 1$ & $150(0)$ & $2.51(3)$ \\
\hline & & 69 & 53 & 1.0 & $1 / 2$ & $1 / 1$ & $1 / 1$ & $1 / 1$ & $1 / 1$ & $1 / 2$ & $1 / 1$ & $1 / 1$ & & \\
\hline & G2-3 (7) & $50^{\circ}$ & 52 & 1.1 & $1 / 1$ & $1 / 1$ & $1 / 3$ & $1 / 2$ & $1 / 2$ & $1 / 2$ & $1 / 1$ & $1 / 1$ & $150(\mathbf{6 0 . 0})$ & ) $2.00(3)$ \\
\hline & & 89 & 46 & 0.9 & $1 / 1$ & $1 / 1$ & $1 / 1$ & $1 / 1$ & $1 / 1$ & $1 / 2$ & $1 / 1$ & $1 / 1$ & & \\
\hline & G2-4 (8) & $70^{\circ}$ & 50 & 1.0 & $1 / 1$ & $1 / 1$ & $1 / 1$ & $1 / 2$ & $1 / 2$ & $1 / 1$ & $1 / 2$ & $1 / 1$ & $148(\mathbf{4 8 . 0})$ & ) $2.07(3)$ \\
\hline & & 89 & 46 & 0.9 & $1 / 1$ & $1 / 1$ & $1 / 1$ & $1 / 1$ & $1 / 1$ & $1 / 2$ & $1 / 1$ & $1 / 1$ & & \\
\hline G3 & G3-1 (9) & $50^{\circ}$ & 52 & 1.1 & $1 / 1$ & $1 / 1$ & $1 / 3$ & $1 / 2$ & $1 / 2$ & $1 / 2$ & $1 / 1$ & $1 / 1$ & $150(0)$ & $2.30(3)$ \\
\hline & & 109 & 51 & 1.0 & $1 / 1$ & $1 / 1$ & $1 / 2$ & $1 / 2$ & $1 / 1$ & $1 / 2$ & $1 / 1$ & $1 / 1$ & & \\
\hline & G3-2(10) & 70 & 50 & 1.0 & $1 / 1$ & $1 / 1$ & $1 / 1$ & $1 / 2$ & $1 / 2$ & $1 / 1$ & $1 / 2$ & $1 / 1$ & $242(0)$ & $2.49(3)$ \\
\hline & & $10 \%$ & 51 & 1.0 & $1 / 1$ & $1 / 1$ & $1 / 2$ & $1 / 2$ & $1 / 1$ & $1 / 2$ & $1 / 1$ & $1 / 1$ & & \\
\hline & G3-3(11) & $50^{\circ}$ & 52 & 1.1 & $1 / 1$ & $1 / 1$ & $1 / 3$ & $1 / 2$ & $1 / 2$ & $1 / 2$ & $1 / 1$ & $1 / 1$ & $199(1.0)$ & $2.17\langle 3\rangle$ \\
\hline & & 129 & 47 & 0.8 & $1 / 1$ & $1 / 1$ & $1 / 2$ & $1 / 1$ & $1 / 1$ & $1 / 1$ & $1 / 1$ & $1 / 1$ & & \\
\hline & G3-4 (12) & $70^{\circ}$ & 50 & 1.0 & $1 / 1$ & $1 / 1$ & $1 / 1$ & $1 / 2$ & $1 / 2$ & $1 / 1$ & $1 / 2$ & $1 / 1$ & $143(0)$ & $2.07(3)$ \\
\hline & & 129 & 47 & 0.8 & $1 / 1$ & $1 / 1$ & $1 / 2$ & $1 / 1$ & $1 / 1$ & $1 / 1$ & $1 / 1$ & $1 / 1$ & & \\
\hline G4 & G4-1 (13) & $90^{\circ}$ & 50 & 1.0 & $1 / 1$ & $1 / 1$ & $1 / 1$ & $1 / 2$ & $1 / 2$ & $1 / 1$ & $1 / 1$ & $1 / 1$ & $150(0)$ & $0.95(1)$ \\
\hline & & $14 \%$ & 53 & 1.2 & $1 / 1$ & $1 / 1$ & $1 / 1$ & $1 / 1$ & $1 / 1$ & $1 / 1$ & $1 / 1$ & $1 / 1$ & & \\
\hline & G4-2 (14) & $110^{\circ}$ & 61 & 1.7 & $1 / 1$ & $1 / 1$ & $1 / 1$ & $1 / 2$ & $1 / 1$ & $1 / 1$ & $1 / 2$ & $1 / 2$ & $150(0)$ & $1.57(2)$ \\
\hline & & 149 & 53 & 1.2 & $1 / 1$ & $1 / 1$ & $1 / 1$ & $1 / 1$ & $1 / 1$ & $1 / 1$ & $1 / 1$ & $1 / 1$ & & \\
\hline & G4-3 (15) & $90^{\circ}$ & 50 & 1.0 & $1 / 1$ & $1 / 1$ & $1 / 1$ & $1 / 2$ & $1 / 2$ & $1 / 1$ & $1 / 1$ & $1 / 1$ & $150(0)$ & $1.48(2)$ \\
\hline & & 169 & 53 & 1.2 & $1 / 1$ & $1 / 1$ & $1 / 1$ & $1 / 2$ & $1 / 1$ & $1 / 1$ & $1 / 2$ & $1 / 1$ & & \\
\hline & G4-4 (16) & $110^{\circ}$ & 61 & 1.7 & $1 / 1$ & $1 / 1$ & $1 / 1$ & $1 / 2$ & $1 / 1$ & $1 / 1$ & $1 / 2$ & $1 / 2$ & $150(0)$ & $1.64(2)$ \\
\hline & & 169 & 53 & 1.2 & $1 / 1$ & $1 / 1$ & $1 / 1$ & $1 / 2$ & $1 / 1$ & $1 / 1$ & $1 / 2$ & $1 / 1$ & & \\
\hline G5 & G5-1 (17) & $130^{\circ}$ & 53 & 1.1 & $1 / 1$ & $1 / 1$ & $1 / 1$ & $1 / 1$ & $1 / 1$ & $1 / 1$ & $1 / 1$ & $1 / 1$ & $149(2.0)$ & 0.95 \\
\hline & & 189 & 53 & 1.5 & $1 / 1$ & $1 / 1$ & $1 / 1$ & $1 / 2$ & $1 / 1$ & $1 / 1$ & $1 / 1$ & $1 / 2$ & & \\
\hline & G5-2(18) & $150^{\circ}$ & 52 & 0.9 & $1 / 1$ & $1 / 1$ & $1 / 1$ & $1 / 2$ & $1 / 1$ & $1 / 2$ & $1 / 2$ & $1 / 1$ & $150(2.7)$ & $1.89(2)$ \\
\hline & & $18 \%$ & 53 & 1.5 & $1 / 1$ & $1 / 1$ & $1 / 1$ & $1 / 2$ & $1 / 1$ & $1 / 1$ & $1 / 1$ & $1 / 2$ & & \\
\hline & G5-3(19) & $130^{\circ}$ & 53 & 1.1 & $1 / 1$ & $1 / 1$ & $1 / 1$ & $1 / 1$ & $1 / 1$ & $1 / 1$ & $1 / 1$ & $1 / 1$ & $150(19.3)$ & $0(1)$ \\
\hline & & $20 \%$ & 54 & 1.4 & $1 / 1$ & $1 / 1$ & $1 / 1$ & $1 / 1$ & $1 / 1$ & $1 / 1$ & $1 / 1$ & $1 / 1$ & & \\
\hline & G5-4 (20) & $150^{\circ}$ & 52 & 0.9 & $1 / 1$ & $1 / 1$ & $1 / 1$ & $1 / 2$ & $1 / 1$ & $1 / 2$ & $1 / 2$ & $1 / 1$ & $150(\mathbf{1 6 . 0})$ & ) $1.50(2)$ \\
\hline & & $20 \%$ & 54 & 1,4 & $1 / 1$ & $1 / 1$ & $1 / 1$ & $1 / 1$ & $1 / 1$ & $1 / 1$ & $1 / 1$ & $1 / 1$ & & \\
\hline
\end{tabular}

$\dagger$ The number in parentheses corresponds to the number of the family used in the subsequent analysis. $\ddagger N$ is the sample size of each family; $E$ is the percentage of progeny with body length less then 151 or more then 175 units. $\S H$ is the mean observed heterozygosity of families; family rank with regard to the mean observed heterozygosity of the progeny in a family is given in parentheses.

given in Table 3 indicating a significant effect of heterozygosity on the body length may be either an artefact or may reflect a hidden relationship between heterozygosity and the between-family component of variance.

\section{Family heterozygosity and progeny body length}

For the analysis of a multilocus heterozygosity effect on the between-family component of variance of body length, all families were divided into three groups 


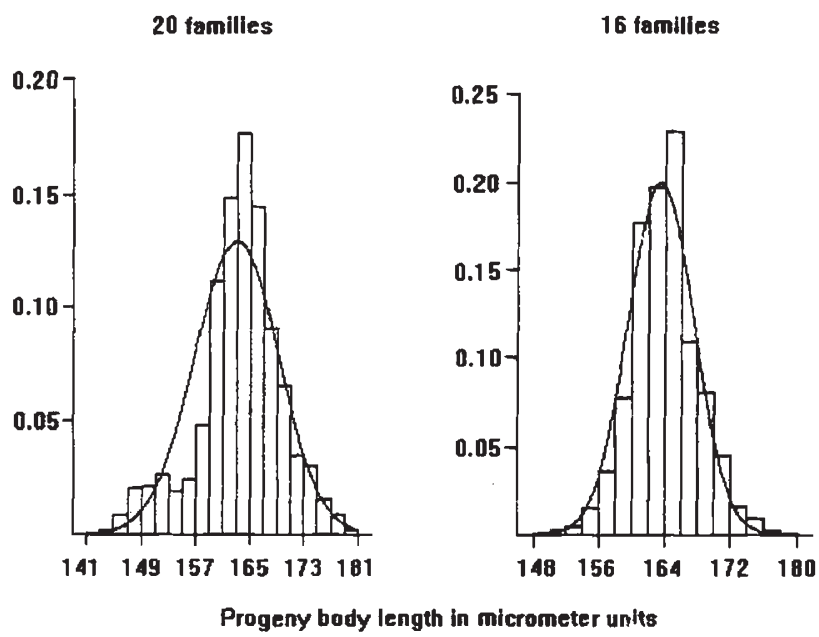

Fig. 1 Distribution of body length of progeny in two sets of families of pink salmon. The expected normal distribution is superimposed on both graphs. according to their mean heterozygosity (Tables 1 and 2 ). The low heterozygosity group included five families with mean heterozygosity not higher than one (heterozygosity rank 1; 787 progeny fry), the intermediate heterozygosity group included seven families with mean heterozygosity ranging from one to two (heterozygosity rank 2; 994 progeny fry), and the high heterozygosity group comprised eight families with mean heterozygosity exceeding two (heterozygosity rank $3 ; 1322$ progeny fry). As was shown by the nested ANOVA, a considerable (over 28 per cent) and statistically significant part of the variance of body length among all 20 families could be attributed to the family heterozygosity (Table 4). However, as was mentioned above, four families have unusually high numbers of progeny with high and low body length values (Tables 1 and 2). One might expect that the effects of family heterozygosity on progeny body length could be

Table 2 Mean body length of pink salmon progeny in the families with different heterozygosities

\begin{tabular}{|c|c|c|c|c|}
\hline \multirow{2}{*}{$\begin{array}{l}\text { Heterozygosity } \\
\text { of father }\end{array}$} & \multicolumn{4}{|c|}{ Heterozygosity of mother } \\
\hline & 0 & 1 & 2 & 3 \\
\hline \multirow[t]{2}{*}{0} & $162.1 \pm 0.3(1 ; 1)$ & $162.8 \pm 0.2(3 ; 1)$ & $166.2 \pm 0.3(17 ; 1)$ & - \\
\hline & $172.0 \pm 0.4(19 ; 1)$ & - & - & - \\
\hline 2 & $163.8 \pm 0.2(13 ; 1)$ & - & $162.9 \pm 0.2(15 ; 2)$ & - \\
\hline \multirow[t]{3}{*}{3} & $165.7 \pm 0.2(2 ; 2)$ & $163.8 \pm 0.4(4 ; 2)$ & $160.8 \pm 0.3(6 ; 3)$ & $163.0 \pm 0.2(10 ; 3)$ \\
\hline & $163.7 \pm 0.3(14 ; 2)$ & $150.6 \pm 0.3(8 ; 3)$ & $163.3 \pm 0.3(16 ; 2)$ & - \\
\hline & $172.6 \pm 0.3(20 ; 2)$ & $162.8 \pm 0.3(12 ; 3)$ & $167.3 \pm 0.3(18 ; 2)$ & - \\
\hline \multirow[t]{2}{*}{4} & - & $149.7 \pm 0.3(7 ; 3)$ & $159.2 \pm 0.3(5 ; 3)$ & $162.2 \pm 0.2(9 ; 3)$ \\
\hline & - & $162.2 \pm 0.2(11 ; 3)$ & - & - \\
\hline
\end{tabular}

The family number and heterozygosity rank (see Table 1) are given in parentheses. Mean values for the excluded families are given in bold.

Table 3 One-way ANOVA of factors influencing pink salmon progeny body length

\begin{tabular}{|c|c|c|c|c|c|}
\hline Source of variation & SS & d.f. & MS & $\mathrm{F}$ & $\mathrm{R}^{2}$ \\
\hline \multicolumn{6}{|l|}{ Set of 20 families } \\
\hline Family & 85183 & 19 & 4483.30 & $407.56^{* * *}$ & 0.7140 \\
\hline Residual & 34024 & 3093 & 11.00 & & \\
\hline Individual heterozygosity of progeny & 6287 & 5 & 1257.44 & $35.94 * * *$ & 0.0590 \\
\hline Residual & 100525 & 2873 & 34.99 & & \\
\hline \multicolumn{6}{|l|}{ Set of 16 families } \\
\hline Family & 14075 & 15 & 938.32 & $89.01^{* * *}$ & 0.3434 \\
\hline Residual & 26872 & 2549 & 10.54 & & \\
\hline Individual heterozygosity of progeny & 816 & 5 & 163.21 & $10.26^{* * *}$ & 0.0210 \\
\hline Residual & 37940 & 2386 & 15.90 & & \\
\hline
\end{tabular}

$R^{2}$ is the coefficient of determination; ${ }^{* * *} P \leqslant 0.001$ 
Table 4 The results of the nested ANOVA of the effects of heterozygosity on pink salmon progeny body length

\begin{tabular}{lrrrrr}
\hline Source of variation & SS & d.f. & MS & F & Q\% \\
\hline Set of 20 families & & & & & \\
$\quad$ Between groups (families) & 62560 & 17 & 3680 & $360.33^{* * *}$ & 71.69 \\
Between subgroups (individual heterozygosity of progeny) & 480 & 47 & 10.21 & 1.01 & 0.01 \\
Residual & 25464 & 2515 & 10.13 & & 28.30 \\
Between groups (heterozygosity rank of families) & 31328 & 2 & 15664 & $4.94^{*}$ & 28.43 \\
Between subgroups (families) & 53856 & 17 & 3168 & $300.65^{* * *}$ & 47.16 \\
Residual & 32592 & 3093 & 10.54 & & 24.41 \\
Set of 16 families & & & & & \\
Between groups (families) & 13152 & 14 & 939.43 & $89.47^{* * *}$ & 37.94 \\
Between subgroups (individual heterozygosity of progeny) & 420 & 40 & 10.50 & 1.03 & 0.05 \\
Residual & 22236 & 2188 & 10.16 & & 62.01 \\
Between groups (heterozygosity rank of families) & 4712 & 2 & 2356 & $3.27^{*}$ & 11.69 \\
Between subgroups (families) & 9360 & 13 & 720 & $70.96^{* * *}$ & 26.91 \\
Residual & 25864 & 2549 & 10.15 & & 61.40 \\
\hline
\end{tabular}

$Q$ is the percentage of the total variance attributable to the factor effect. Heterozygosity rank of families is given in Tables 1 and 2 .

${ }^{*} P \leqslant 0.05,{ }^{* * *} P \leqslant 0.001$.

mainly attributed to the contribution of these four families. To test this, the same analysis was performed for the set of 16 families only, but this did not alter the relationships (Table 4). For this set of families the differences among the families in their mean heterozygosity account for up to 12 per cent of the total variance of body length.

Figure 2 shows the relationship between the mean body length in the progeny and the mean heterozygosity among the 16 families. The experimental curve is satisfactorily approximated by a quadratic regression equation. Here, two main points are noteworthy. First, the progeny of all of the six families with high heterozygosity have low mean body length. In four families of this group the mean body length is significantly lower than the overall mean. Secondly, in four out of six families with intermediate heterozygosity the body length of the progeny is higher than the overall mean and for three of these families this difference is statistically significant. Consequently, the progeny of the families with the intermediate heterozygosity tend to have maximal body length. At the same time, we did not find a significant correlation between the mean heterozygosity of the 16 families and their coefficients of variation of body length $(r=0.0563 ; P>0.05)$.

\section{Single-locus heterozygosity}

Another point of interest is the possible single-locus effects on the relationship between progeny body length and heterozygosity. To analyse this, we considered the groups of families polymorphic for parti-

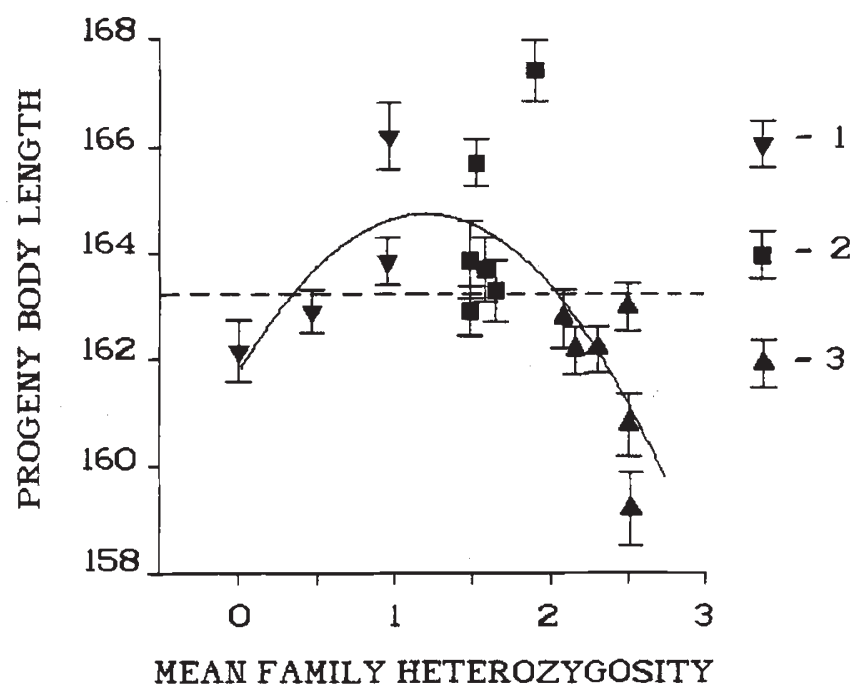

Fig. 2 The relationship between mean family heterozygosity and progeny body length of pink salmon: 1 , families with low heterozygosity; 2 , families with intermediate heterozygosity; 3 , families with high heterozygosity. The line indicates the mean body length value for all the progeny examined. Linear fit (not shown) $y=164.9-0.87 x ; F_{1,2563}=66.79, P<0.001$; $R^{2}=0.0253$; quadratic fit $y=161.7+5.51 x-2.27 x^{2}$; $F_{2,2562}=189.23, P<0.0001, R^{2}=0.1290$.

cular loci. Table 5 presents the results of the two-way ANOVA for the set of 16 families estimating simultaneously the effects of single-locus heterozygosity and interfamily differences on progeny body length. For two loci, $M D H-3^{*}$ and $P G D H^{*}$, the effect of heterozygosity on the body length was significant. The 
Table 5 The results of two-way ANOva of the single-locus effects of progeny heterozygosity on the body length for the set of 16 families of pink salmon

\begin{tabular}{lcccc}
\hline & & \multicolumn{3}{c}{ Source of variation $\ddagger$} \\
\cline { 3 - 5 } Locus & $N \dagger$ & Heterozygosity & Family & Interaction \\
\hline$G 3 P D H^{*}$ & $300(2)$ & 1.04 & $15.02^{* * *}$ & 0.04 \\
$M D H-3^{*}$ & $278(2)$ & $4.47^{*}$ & $7.72^{* *}$ & 0.94 \\
$M D H-4^{*}$ & $1149(7)$ & 0.03 & $44.42^{* * *}$ & 0.88 \\
$M E P-2^{*}$ & $1879(12)$ & 0.65 & $111.39^{* * *}$ & 0.87 \\
$P G D H^{*}$ & $1787(11)$ & $5.74^{*}$ & $42.31^{* * *}$ & 1.60 \\
$P G M^{*}$ & $1017(6)$ & 0.03 & $209.46^{* * *}$ & 1.14 \\
$G P I-2^{*}$ & $1088(7)$ & 0.35 & $103.99^{* * *}$ & 1.16 \\
$F D H^{*}$ & $599(4)$ & 1.78 & $109.77^{* * *}$ & 2.50 \\
\hline
\end{tabular}

$\dagger$ The number of families polymorphic for the given locus is shown in parentheses. $\ddagger F$-values are presented in all columns.

${ }^{*} P \leqslant 0.05,{ }^{* *} P \leqslant 0.01,{ }^{* * *} P \leqslant 0.001$.

$P G D H^{*}$ homozygotes tend to have larger body length values as compared with the heterozygotes. For $\mathrm{MDH}^{-}$ $3^{*}$ this trend was reversed: the heterozygotes at this locus are larger than homozygotes. However, as only two families had $M D H-3^{*}$ heterozygotes (or double heterozygotes at the $\mathrm{MDH}-3,4^{*}$ loci), this might be a chance relationship which would not significantly influence the association between the mean heterozygosity and the body length. At the same time, in eight out of 11 families polymorphic for $P G D H^{*}$, the body length in the homozygotes was higher than in heterozygotes (162.9 \pm 0.1 for homozygotes and $162.5 \pm 0.1$ for heterozygotes; $\left.t_{1787}=2.42, P<0.05\right)$. The body length seems to be affected by the $P G D H^{*}$ locus itself or some gene/genes closely linked to it. The $P G D H^{*}$ heterozygotes, which have lower body length, are more frequent in highly heterozygous families. One might expect that the decline in the progeny body length with the increase of the mean heterozygosity results from the effect of only one locus, $P G D H^{*}$. To test this, we excluded $P G D H^{*}$ from further analysis, but this did not alter the relationships demonstrated for the eight loci. Repeat nested ANOVA showed that the individual heterozygosity estimated for the set of seven polymorphic loci does not significantly influence the progeny body length within families while the mean family heterozygosity makes a considerable contribution to the between-family variance of body length. The relationship between the mean family heterozygosity and the body length can be approximated by a quadratic fit $y=162.6+4.59 x-2.39 x^{2}$; $F_{2,2562}=82.16 ; P<0.001$, which is close to that for the whole set of loci (see Fig. 2).

\section{Interlocus interactions}

As was shown earlier, the relationship between individual heterozygosity and quantitative traits can be greatly affected by interlocus interactions (Dubrova \& Gavrilets, 1989). To test this hypothesis, the coefficients of correlation between the individual heterozygosity and the progeny body length within families with high and intermediate heterozygosity were estimated (Fig. 3). None of the coefficients of correlation differed significantly from zero. Nevertheless, in five out of six families with intermediate heterozygosity the coefficients of correlation were negative while in four out of six highly heterozygous families they were positive. This trend is statistically significant $(P=0.025$ by the Kruskal-Wallis test), and indirectly confirms that the interaction of polymorphic loci in the compared groups is different.

\section{Discussion}

The results of this study indicate a statistically significant association of multilocus family heterozygosity and progeny body length in pink salmon. Heterozygosity affects the between-family component of variance of body length.

The relationships between heterozygosity and the progeny body length were found in our previous experiments using eight families of pink salmon families with 598 progeny and only four polymorphic loci instead of the eight used in the present study (Kartavtsev, 1990; Kartavtsev et al., 1990; Altukhov et al., 1991). The latter circumstance makes comparison between the studies difficult, especially in view of the lack of $P G D H^{*}$ variation in the families analysed earlier; as was shown in the present study, heterozygosity at this locus has a negative effect on the progeny body length. In addition, in the earlier analysis the between-family component of variance was not considered. The analysis of the present data, without division into families, gives results comparable with the earlier ones cited above. In fact, the coefficient of correlation between individual heterozygosity and progeny body length estimated for the pooled data of the present work is equal to $-0.1060, P<0.001$. However, as shown in Table 4, this value could reflect only the effect of heterozygosity on the between-family component of variance. To test this by excluding the differences between families, the body length of each fry was transformed to $z_{i j}=\left(x_{i j}-x_{j}\right) / \sigma_{j}$, where $x_{i j}$ is the body length of the $i$ th fry from the $j$ th family, $x_{j}$ and $\sigma_{j}$ are respectively the mean body length and its standard deviation in the $j$ th family. The coefficient of correlations between the heterozygosity and the transformed body 


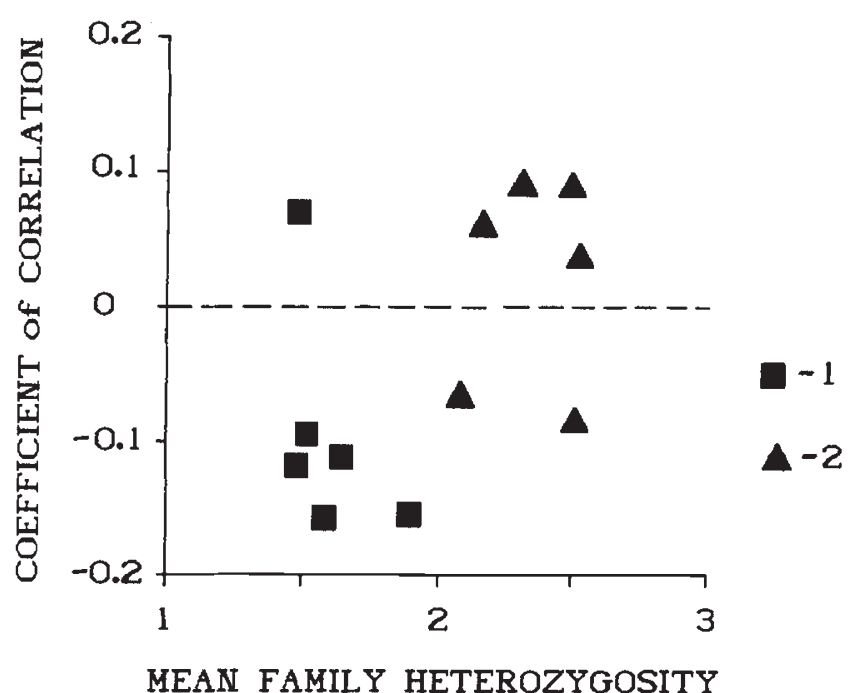

Fig. 3 The relationship between the mean family heterozygosity of pink salmon and the coefficients of correlation between body length and individual heterozygosity: 1, families with intermediate heterozygosity; 2 , families with high heterozygosity.

length did not significantly differ from zero: $r=-0.0172, P>0.05$. Thus, this result provides additional confirmation of the fact that the correlations between the body length and heterozygosity demonstrated in this study is related to the betweenfamily component of variance.

The associations between heterozygosity and phenotypic characters has been studied in families of rainbow trout (Leary et al., 1987; Ferguson, 1992) and marine bivalves (Beaumont et al., 1983; Gaffney \& Scott, 1984; Foltz \& Chatry, 1986; Mallet et al., 1986). In agreement with our data, no association was detected between heterozygosity and growth rate in full- and half-sib families of several species of marine bivalves (Beaumont et al., 1983; Gaffney \& Scott, 1984; Foltz \& Chatry, 1986). On the contrary, the positive relationship between heterozygosity and developmental stability was found to be as strong among full-sibs of pink salmon as it is among individuals randomly sampled from populations (Leary et al., 1987). The discrepancy between the results could be ascribed to the different phenotypic characters scored in these experiments.

The second noteworthy point is that the mean body length of the progeny from the families with intermediate heterozygosity is much larger than that in the highly heterozygous families. The growth rate of the progeny from the families with intermediate heterozygosity is probably higher than that of the fish from highly heterozygous families. This result contradicts the pre- dictions of the overdominant model used in some studies to explain the observed correlation between individual heterozygosity and growth rate (Zouros \& Foltz, 1987; Altukhov, 1989b). Earlier it was shown that epistasis can considerably modify the relationships between individual heterozygosity and quantitative traits (Dubrova \& Gavrilets, 1989). This kind of interlocus interaction occurred in hybrid genotypes that were previously either absent or very rare in native human populations. Highly heterozygous families are quite rare in pink salmon populations (Altukhov et al., 1987). The probability of occurrence of fish with certain values of individual heterozygosity can be estimated on the basis of the genotype distributions of the eight polymorphic loci in the spawning population of the Bolshoy Takoy River (the Sokolovsky hatchery) in 1989 (the computation method is given by Chakraborty, 1981). Table 2 shows that the highly heterozygous progeny belonged to the males and females with an individual heterozygosity of three to four and one to three, respectively. The corresponding probabilities of incidence of fish with such genotypes were 0.07 and 0.65 . Then the probability of random mating of such parents would be $0.07 \times 0.65=0.05$. Thus, these genotype combinations, artificially created in our experiment, rarely occur in natural populations. The unique combination of alleles at the polymorphic loci examined could result in epistasis affecting variation in quantitative traits, in particular, in the progeny body length. The above analysis of correlation between the body length and individual heterozygosity within families showed statistically significant differences between the progeny of the families with the intermediate and high heterozygosity. This evidence confirms the hypothesis that the body length decline results from an interlocus interaction in the highly heterozygous progeny.

Finally, our data present one more experimental verification of the hypothesis of an intermediate (and not maximal) level of genetic variability which is optimal for a population and is maintained by natural selection (Altukhov et al., 1987; Altukhov, 1989a,b; Dubrova et al., 1990, 1991a,b). The fry body length is a character related to fitness, and fry with low body length have lower viability (Beacham, 1988; Danzmann et al., 1988). Our results demonstrate that the pink salmon fry with low body length are more frequent in the families with high heterozygosity. Therefore, natural selection acting against the fry with low body length influences the genetic diversity of a population and maintains it at an optimum for the population level. An analogous conclusion was drawn in the study of the progeny mortality in pink salmon families with different heterozygosities: the minimal mortality 
was recorded in the families with intermediate heterozygosity (Altukhov, 1989b; Kartavtsev et al., 1990; Altukhov et al., 1991). Moreover, similar results were obtained in human populations in the study of the relationship between heterozygosity and fertility (Dubrova et al., 1990) and in the analysis of the effect of maternal heterozygosity on the anthropometric traits in newborns (Dubrova et al., 1991b). Thus, the hypothesis of the maximal fitness of individuals with an intermediate (optimal) level of genetic variation is verified for populations of various organisms and is probably of general significance.

These results, as well as the previous ones (Altukhov, 1989a; Kartavtsev, 1990; Kartavtsev et al., 1990; Altukhov et al., 1991) may be applied to fish breeding. It is evident, as we have previously discussed (Altukhov \& Salmenkova, 1990) that the progeny with the lowest mortality rate can be obtained from spawners with intermediate levels of heterozygosity. In this case the population genetic diversity of $O$. gorbuscha can be preserved in the progeny to full extent.

\section{Acknowledgments}

We thank B. A. Kalabushkin for useful comments and G. A. Rubtsova for technical assistance in some experiments. This work was supported by a grant from the Russian State Programme 'Frontiers in Genetics' and the Russian Fund of Basic Research to Y.P.A. and E.A.S.

\section{References}

Altukhov, Y. P. 1989a. Genetic Processes in Populations. Nauka, Moscow.

ALTUKHOV, Y. P. 1989b. Balancing selection as the factor of maintenance of allozyme polymorphism. Adv. Modern Biol. (Russia), 107, 323-340.

ALTUKHOV, Y. P. AND SALMENKOVA, E. A. 1990. The genetic structure of salmon populations. Aquaculture, 98, 11-40.

ALTUKHOV, Y. P., SALMENKOVA, E. A. AND KARTAVTSEV, Y. F. 1991. The association of allozyme heterozygosity with viability and growth rate in pink salmon. Cytol. Genet. (Ukraine), 25, 47-51.

ALTUKHOV, Y. P., SALMENKOVA, E. A., OMEL'CHENKo,V. T., RUBTSOVA, G. A. AND DUBROVA, Y. E. 1987. Balancing selection as a probable factor of maintenance of homogeneity of allozyme allele frequencies in populations of Pacific pink salmon Oncorhynchus gorbuscha Walb. Genetika (Russia), 23, 1884-1896.

BEACHAM, T. D. 1988. A genetic analysis of early development in pink (Oncorhynchus gorbuscha) and chum salmon (Oncorhynchus keta) at three different temperatures. Genome, 30, 89-96.

BEAUMONT, A. R., BEVERIDGE, C. M. AND BUDD, M. D. 1983. Selec- tion and heterozygosity within single families of the mussel Mytilus edulis (L). Mar. Biol. Lett., 4, 151-161.

CHAKRABORTY, R. 1981. The distribution of the number of heterozygous loci in an individual in natural populations. Genetics, 98, 461-466.

CHAKRABORTY, R. 1987. Biochemical heterozygosity and phenotypic variability of polygenic traits. Heredity, $\mathbf{5 9}$, 19-28.

DANZMANN, R. G., FERGUSON, M. M. AND ALLENDORF, F. W. 1986. Does enzyme heterozygosity influence developmental rate in rainbow trout? Heredity, 56, 417-426.

DANZMANN, R. G., FERGUSON, M. M. AND ALLENDORF, F. W. 1987. Heterozygosity and oxygen consumption rate as predictors of growth and developmental rate in rainbow trout. Physiol. Zool., 60, 211-220.

DANZMANN, R. D., FERGUSON, M. M. AND ALLENDORF, F. W. 1988. Heterozygosity and components of fitness in a strain of rainbow trout. Biol. J. Linn. Soc., 33, 285-304.

DUBROVA, Y. E., DAMBUEVA, I. K., KHOLOD, O. N., PROKHOROVSKYA, V D. AND PUSHKINA, E. 1. 1991b. The effect of maternal heterozygosity on variation of anthropometric traits in newborns. Genetika (Russia), 27, 2168-2176.

DUBROVA, Y. E., DAMBUEVA, I. K., KHOLOD, O. N., PROKHOROVSKYA, V. D., PUSHKINA, E. I. AND BLANK, M. L. 1991a. The effect of heterozygosity in newborns on variation in anthropometric traits. Genetika (Russia), 27, 2157-2167.

DUBROVA, Y. E. AND GAVRILETS, S. Y. 1989. Epistatic gene interactions in offspring of distant marriages contracted within the Russian population. Proc. Acad. Sci. U.S.S.R., 309, 211 215.

DUBROVA Y. E., KARAFET, T. M., SUKERNIK, R. I. AND GOL'TSOVA, T. V. 1990. Heterozygosity and fertility relationship in the Forest Nentzy and Nganasany. Genetika (Russia), 26, 122-129.

FERGUSON, M. M. 1992. Enzyme heterozygosity and growth in rainbow trout: genetic and physiological explanations. Heredity, 68, 115-122.

FOLTZ, D. W. AND CHATRY, M. 1986. Genetic heterozygosity and growth rate in Louisiana oysters (Crassostrea virginica). Aquaculture, 57, 261-269.

GAFFNEY, P. M. AND SCOTT, T. M. 1984. Genetic heterozygosity and production traits in natural and hatchery populations of bivalves. Aquaculture, 42, 289-302.

HOllaNDER, M. AND WOLFE, D. A. 1973. Nonparametric Statistical Methods. Wiley, New York.

KARTAVTSEV, Y. F. 1990. Allozyme heterozygosity and morphological homeostasis in pink salmon, Oncorhynchus gorbuscha (Pisces: Salmonidae). Genetika (Russia), 26, 1399-1407.

KARTAVTSEV, Y. F., SAlmenkova, E. A., RUbTSOVA, G. A. AND AFANAS'EV, K. I. 1990. Family analysis of allozyme variation and its relation to body size and progeny viability in pink salmon, Oncorhynchus gorbuscha (Walb.). Genetika (Russia), 26, 1610-1619.

LEARY, R. F., ALlENDORF, F. W. AND KNUDSEN K. L. 1987. Differences in inbreeding coefficients do not explain the association between heterozygosity at allozyme loci and developmental stability in rainbow trout. Evolution, $\mathbf{4 1}$, 1413-1415. 
Lerner, I. M. 1954. Genetic Homeostasis. Oliver and Boyd, Edinburgh.

LIVSHITS, G. AND KOBYLIANSKY, E. 1984. Biochemical heterozygosity as a predictor of developmental homeostasis in man. Ann. hum. Genet., 48, 173-184.

MALLET, A. L., ZOUROS E., GARTNER-KERKAY, K. E. AND FREEMAN, K. R. 1986. Genetics of growth in blue mussel: family and enzyme-heterozygosity effects. Mar. Biol., 92, 475-482.

MITTON, J. B. AND GRANT, M. C. 1984. Association among protein heterozygosity, growth rate, and developmental homeostasis. Ann. Rev. Ecol. Syst., 15, 479-499.

SAlmenKova, E. A. AND OMELChenKo, v. T. 1983. Genetic analysis of some polymorphic enzyme systems in pink salmon, Oncorhynchus gorbuscha (Walbaum). In: Burtsev I. A. (ed.) Genetics of Commercial and Cultivated Species, pp. 8-15. Lyogkaya i Pishchevaya Promyshlennost, Moscow.

SMOUSE, P. E. 1986. The fitness consequences of multiplelocus heterozygosity under the multiplicative overdominance and inbreeding depression models. Evolution, 40, 946-957.
SOKAL, R. R. AND ROHLF, F. J. 1981. Biometry, 2nd edn. W. H. Freeman, New York.

ZHIVOTOVSKY, L. A., AFANAS'EV, K. I. AND RUBTSOVA, G. A. 1987. Factors of variability of larval size and weight in pink salmon. Proc. of the State Res. Inst. of Lake and River Fisheries, 261, 66-76.

zOUROs, E. 1987. On the relationship between heterozygosity and heterosis: an evaluation of the evidence from marine molluscs. In: Rattazzi, M. C., Scandalios, J. C. and Whitt, G. S. (eds) Isozymes: Current Topics in Biological and Medical Research, vol. 15, pp. 255-270. A. R. Liss, New York.

zouros, E. AND FOLTZ, D. w. 1987. The use of allelic isozyme variation for the study of heterosis. In: Rattazzi, M. C., Scandalios, J. C. and Whitt, G. S. (eds) Isozymes: Current Topics in Biological and Medical Research, vol. 13, pp. 1-59. A.R. Liss, New York.

ZOUROS, E., SINGH, S. M. AND MILES, H. E. 1980. Growth rate in oysters: an overdominant phenotype and its possible explanations. Evolution, 34, 856-867. 